\title{
Basal entrainment by Newtonian gravity-driven flows
}

\author{
Belinda M. Bates, Nicolas Andreini, and Christophe Ancey \\ École Polytechnique Fédérale de Lausanne, Écublens, 1015 Lausanne, Switzerland
}

(Received 8 January 2016; accepted 9 April 2016; published online 2 May 2016)

\begin{abstract}
Gravity-driven flows can erode the bed along which they descend and increase their mass by a factor of 10 or more. This process is called "basal entrainment." Although documented by field observations and laboratory experiments, it remains poorly understood. This paper examines what happens when a viscous gravity-driven flow generated by releasing a fixed volume of incompressible Newtonian fluid encounters a stationary layer (composed of fluid with the same density and viscosity). Models based on depth-averaged mass and momentum balance equations deal with bed-flow interfaces as shock waves. In contrast, we use an approach involving the long-wave approximation of the Navier-Stokes equations (lubrication theory), and in this context, bed-flow interfaces are acceleration waves that move quickly across thin stationary layers. The incoming flow digs down into the bed, pushing up downstream material, thus advancing the flow front. Extending the method used by Huppert ["The propagation of two-dimensional and axisymmetric viscous gravity currents over a rigid horizontal surface," J. Fluid Mech. 121, 43-58 (1982)] for modeling viscous dam-break waves, we end up with a nonlinear diffusion equation for the flow depth, which is solved numerically. Theory is compared with experimental results. Excellent agreement is found in the limit of low Reynolds numbers (i.e., for flow Reynolds numbers lower than 20) for the front position over time and flow depth profile. Published by AIP Publishing. [http://dx.doi.org/10.1063/1.4947242]
\end{abstract}

\section{INTRODUCTION}

A fundamental property of free shear turbulent flows (e.g., jets and plumes) is that they can entrain ambient fluid through their boundaries, and such entrainment causes them to increase their volume. The mechanisms of ambient fluid incorporation and mixing are fairly well understood in uniform (unstratified and nonrotating) environment: shear-driven instabilities (e.g., KelvinHelmholtz billows) developing along the interface between the flow and quiescent fluid capture parcels of ambient fluid and incorporate them into the flow. ${ }^{1}$ Although the details of such incorporation are complicated and involve different length scales (from turbulent to laminar scales), the bulk entrainment rate $q$ can be related to macroscopic flow properties such as the mean flow velocity $U$ and interface area $S: q=e S U$, where $e$ is the (dimensionless) entrainment coefficient. ${ }^{2}$ The success of this formulation lies in the simple dependence of the entrainment rate on the macroscopic properties through dimensionless numbers (e.g., the Richardson, Froude, and Reynolds numbers), which explains why it is routinely used for describing industrial and natural flows. ${ }^{3-5}$

Another form of entrainment-hereafter referred to as basal entrainment-also occurs in natural buoyancy-driven flows down sloping beds (e.g., turbidity currents in the ocean, snow avalanches and debris flows on mountain slopes). Many of these flows can erode the bed along which they descend and thereby increase the volume of material initially mobilized. A field survey conducted by Sovilla, Burlando, and Bartelt ${ }^{6}$ revealed that avalanche mass could increase by a factor from 1 to 12 (the relative mass ratio between release and runout was 4.6 on average in their survey). For debris flows, mass increase factors as large as 50 (between initiation and deposition) have been reported. ${ }^{7}$ Field observations and scaling considerations have provided ample evidence that basal entrainment plays a key part in the dynamics of gravity driven flows. Two examples illustrate this link between mass (or volume) and dynamics. First, the distance $L$ traveled by the flowing mass is usually related to the total volume $L \propto V^{n}$ with $n$ in the $0.25-0.39$ range. ${ }^{8}$ Further, erosive 
flows have higher mobility (or undergo lower bed resistance) than constant-volume flows. ${ }^{9}$ Second, gravity driven flows involving turbulent particle suspensions (e.g., turbidity currents in the ocean, powder snow avalanche in mountain areas) increase their volume by entraining ambient fluid and scouring the bed. Basal entrainment is a necessary condition for the flow to counterbalance the dilution effect induced by the incorporation of ambient fluid. In the absence of basal entrainment, the current dies out as the buoyancy force decreases. ${ }^{10,11}$

In contrast to entrainment in free shear turbulent flows, little consensus has emerged as to how gravity-driven flows erode their beds. Among the various scenarios proposed so far, three mechanisms seem most plausible: ${ }^{7,12,13}$ (a) entrainment by progressive erosion of the bed along the interface between the flow and streambed, ${ }^{14-17}$ (b) massive entrainment during passage of the front, ${ }^{18}$ (c) stepwise or slab-by-slab failure underneath the leading edge. ${ }^{19,20}$ Recent field surveys provided evidence that for glaciers and debris flows, the primary mode of entrainment is progressive bed erosion, ${ }^{21,22}$ while for snow avalanches, ${ }^{6,23,24}$ entrainment occurred within the tip region (mostly by frontal ploughing).

Elaborating a consistent theoretical framework for modeling basal entrainment has attracted considerable attention in recent years. ${ }^{25}$ The most common approach involves depth-integrated mass and momentum balance equations (an approach also referred to as the Saint-Venant approach in reference to the pioneering work of Adhémar Barré de Saint-Venant to model flood propagation in rivers). Within the Saint-Venant framework, the mass balance equation reads ${ }^{25-28}$

$$
\frac{\partial h}{\partial t}+\frac{\partial}{\partial x}(h \bar{u})=E,
$$

where $E$ denotes the entrainment rate $\left[\mathrm{m} \mathrm{s}^{-1}\right], \bar{u}$ the depth-averaged velocity, $h$ the flow depth, $t$ time, $x$ the downstream position (the $x$-axis lies approximately parallel to the bed). While this equation can be derived rigorously by taking the depth-average of the local mass balance equation and applying proper kinematic boundary conditions, it is not closed as the entrainment rate $E$ is unresolved. Little is known about the parametric dependence of $E$ on the flow variables $\bar{u}$ and $h$. For saturated granular materials, Iverson ${ }^{15}$ used scaling arguments to suggest that $E \propto \bar{u}^{-1}$, but the most recent experiments focusing on dry granular flows reveal more complicated behavior. ${ }^{9}$ For turbidity currents, Parker et al. ${ }^{14}$ found that $E$ is a strongly varying function of the bottom shear stress (or shear velocity), but there is considerable scatter among their data such that this function provides only a mean trend.

In the absence of closure equations for $E$, authors have questioned the relevance of using a mass balance in the form given by (1). For instance, for dry granular flows, Capart, Hung, and Stark $^{29}$ suggested tracking the interface between the stationary layer and flow by using the depth-averaged kinetic energy balance equation, while mass conservation was considered over a large control volume including the stationary and flowing grains. There are further impediments to the use of depth-averaged mass balance equation (1).

First, erosion is a process along an interface, which involves local variables such as the shear rate, shear and normal stresses whereas the depth-averaged governing equations rely on the global flow variables $\bar{u}$ and $h$. Any averaging procedure implies loss of information and there is no guarantee that the entrainment rate can be expressed in the form of a simple algebraic relationship $E=f(\bar{u}, h)$.

Second, the bed-flow interface may change nature when taking the depth-average of local conservation equations. For incompressible fluids that satisfy the no-slip condition at solid boundaries, the bed-flow interface can be defined as the surface along which the particles start to be entrained and accelerate from zero to a finite velocity. As sketched in Figure 1, the local velocity field is continuous in the vicinity of the interface, while the shear rate exhibits a jump across the interface. The interface is thus a second-order singular surface called an acceleration wave (as first-order kinematic fields are continuous, but those of order 2 are discontinuous). ${ }^{30}$ For compressible materials and fluids that do not satisfy the no-slip condition, the bed-flow interface is a first-order singular surface called a shock wave,$^{30}$ associated with a jump in the fluid velocity and/or density. In the Saint-Venant approach, the moving material flows at a constant velocity $\bar{u}(x, t)$ across the depth, and so there is a velocity jump between the bed and flow. In that case, the bed-flow interface is also a shock wave and so, for incompressible Newtonian fluids, it changes nature.

Third, shock waves are mathematical idealizations of transition layers seen as infinitely thin. Actually, transition layers have a finite thickness (in the present case, the transition layer is the 


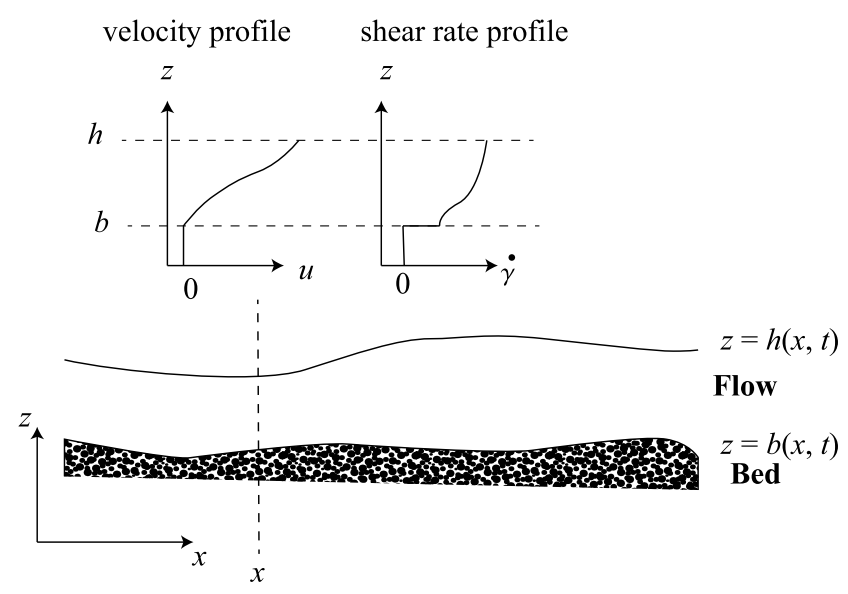

FIG. 1. Sketch of the bed-flow interface. When the no-slip condition applies, the shear rate profile is discontinuous across the bed-flow interface, while the velocity profile is continuous (no jump).

layer within which bed particles accelerate vigorously and reach the bulk flow velocity $\bar{u}$ ). When in practice, the thickness of the transition layer is not much smaller than the eroding flow's depth scale, determining the position of the bed-flow interface is complicated. For instance, in experiments conducted by Armanini et al. ${ }^{31}$ on saturated granular flows and loose beds, there was no sharp transition between motionless and moving particles, which made it difficult to estimate the thickness of the transition layer and the position of the bed-flow interface.

For all these reasons, it is advantageous to address a simple problem of basal entrainment, for which we do not need to appeal to the Saint-Venant approach to derive the equations of motion. In this paper, we investigate the motion of a finite volume of an incompressible Newtonian liquid suddenly released on a horizontal surface. This is the so-called dam-break problem, which has been intensively studied in recent years, especially in the context of lubrication theory. ${ }^{32-39} \mathrm{In}$ contrast to the Saint-Venant approach, the governing equations are obtained by expanding the local mass and momentum equations into power series of the aspect-ratio number $\epsilon=H_{*} / L_{*}$, where $H_{*}$ and $L_{*}$ are flow depth and length scales, respectively, and seeking matched asymptotic solutions. In the absence of entrainment, there is a self-similar solution to the first-order problem, referred to as Huppert's solution. ${ }^{34}$ The innovative point of this paper is to investigate the effect of basal entrainment on the flow dynamics: let us imagine that over a certain length $\left(\ell_{\text {bed }}\right.$ in the following), the flow can erode a finite-thickness layer composed of the same liquid. How are the flow dynamics (e.g., front position with time $x_{F}(t)$, flow depth profile $\left.h(x, t)\right)$ altered by basal entrainment? Can we track the bed-flow interface $b(x, t)$ and estimate an entrainment rate?

We begin by outlining Huppert's approach to viscous dam-break waves and by addressing how it can be extended to take basal entrainment into account (see Sec. II). While the dam-break problem for homogeneous Newtonian fluids is well known within lubrication theory, basal entrainment involves tracking a moving interface (which is an acceleration wave), and so adds considerable complexity to the initial problem. Scaling considerations demonstrate that this interface moves quickly and rapidly reaches the fixed bottom when the stationary layer is shallow or comparable to the flow depth. On this basis, one can justify ignoring the initial phase during which the acceleration wave propagates throughout the stationary layer and sets fluid in motion. It is then straightforward to extend Huppert's approach. We will then continue with a careful description of the experimental protocol in Sec. III. In Sec. IV, we present and discuss our experimental results.

\section{THEORY}

\section{A. General problem}

Let us consider that at time $t=t_{0}$, an elongated Newtonian gravity-driven flow encounters a stationary layer of Newtonian liquid bounded by a lower solid boundary $B(x)$ and the free boundary 


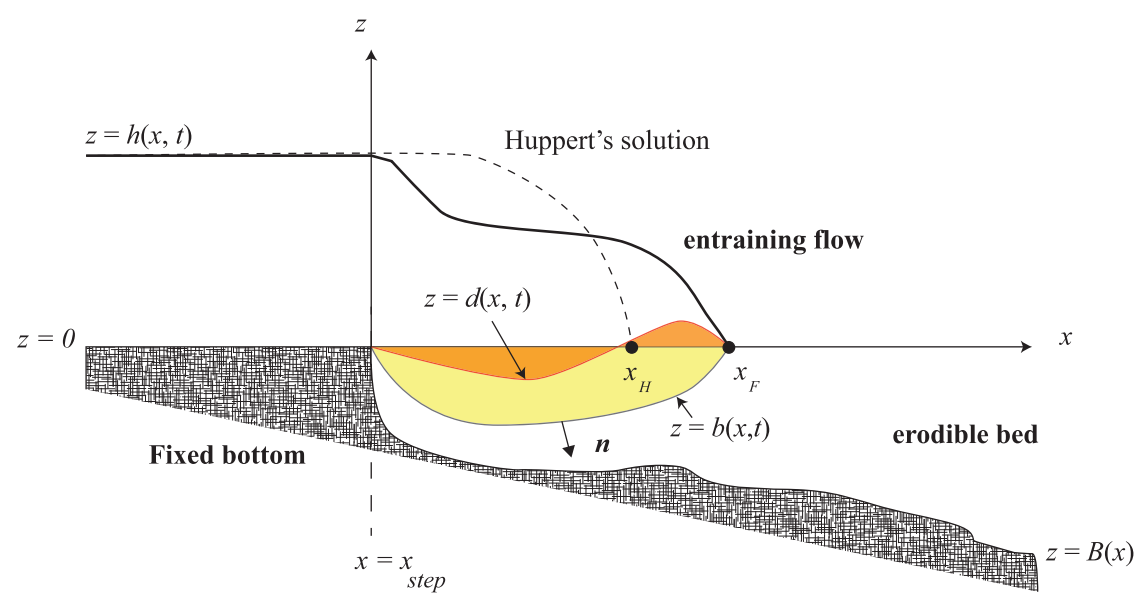

FIG. 2. Configuration of the flow. For $x \geq x_{\text {step }}$, the viscous gravity current is in contact with a stationary layer composed of the same material. The interface between the flow and bed is an acceleration wave of equation $z=b(x, t)$. The fixed bottom is denoted by $B(x)$. A material surface is the contact discontinuity $d(x, t)$, which can be tracked experimentally by using colored fluids (see Sec. III).

$z=0$ (see Fig. 2). The Newtonian flow spreads along the stationary layer and entrains part of it. The flow and stationary bed are composed of the same incompressible Newtonian liquid of viscosity $\mu$ and density $\varrho$. Surface tension effects are assumed to be negligible compared to viscous forces.

Our analysis takes its inspiration from Huppert's mode ${ }^{34}$ of viscous gravity-driven flows, and so we will first recall how Huppert's solution is derived within the framework of lubrication theory. Then, we show how this solution can be extended to take basal entrainment into account when the stationary layer is shallow or its thickness is comparable to the flow depth. In both cases, we consider a two-dimensional flow in $x$ and $z$, ignoring the cross-plane direction $y$.

\section{B. Huppert's solution for rigid bases}

The elongated viscous flow is created by suddenly releasing a fixed volume of Newtonian liquid from a reservoir at time $t=0$. Initially, this liquid flows over a rigid solid boundary until the front reaches the stationary layer at $x=x_{\text {step }}$. Within lubrication theory, i.e., in the limit of low Reynolds and small aspect ratio numbers (the flow Reynolds number is $R e=U_{*} H_{*} / v$ where $U_{*}$ denotes the velocity scale and $v=\mu / \varrho),{ }^{34}$ motion is dictated by the balance between the streamwise gradient of the pressure $\partial_{x} p$ and the cross-stream gradient of the shear stress $\partial_{y} \tau$, where $p$ and $\tau$ denote the fluid pressure and shear stress, respectively. To first order, the pressure adopts a hydrostatic form $p=\varrho g(h-z)$ and the shear stress reads $\tau=\mu \partial_{y} u$ (where $u$ denotes the horizontal velocity component). In this way we deduce the velocity scale

$$
\frac{\partial p}{\partial x} \sim \mu \frac{\partial^{2} u}{\partial y^{2}} \Rightarrow U_{*} \sim \frac{\epsilon^{3} L_{*}^{2} g}{v} .
$$

The first-order governing equations are then obtained by scaling the Navier-Stokes equations and removing terms of order $\epsilon$ or higher,

$$
\begin{aligned}
\frac{\partial \hat{p}}{\partial \hat{z}} & =-1, \\
\frac{\partial^{2} \hat{u}}{\partial \hat{z}^{2}} & =\frac{\partial \hat{p}}{\partial \hat{x}},
\end{aligned}
$$

where symbols with a hat represent dimensionless variables

$$
x \rightarrow L_{*} \hat{x}, \quad(h, z) \rightarrow H_{*}(\hat{h}, \hat{z}), \quad u \rightarrow U_{*} \hat{u}, w \rightarrow \epsilon U_{*} \hat{w}, \quad p \rightarrow \varrho g \epsilon L_{*} \hat{p}, \quad t \rightarrow T_{*} \hat{t}, \quad V_{0} \rightarrow H_{*} L_{*} \hat{V}
$$


with $t$ time, $(u, w)$ the velocity components in the Cartesian coordinate system of Fig. $2, h(x, t)$ the free surface, and $V_{0}$ the total volume of fluid (per unit width) released by opening the reservoir gate. Conservation of mass leads to an exact equation for $\hat{h}$

$$
\frac{\partial \hat{h}}{\partial \hat{t}}-\frac{1}{3} \frac{\partial}{\partial \hat{x}}\left(\hat{h}^{3} \frac{\partial \hat{h}}{\partial \hat{x}}\right)=0 .
$$

There exists a similarity solution to this nonlinear diffusion equation when the volume of fluid $V_{0}$ is fixed. ${ }^{33,34}$ This similarity solution for the flow depth is referred to as Huppert's solution (it is also known as the Barenblatt-Pattle solution in nonlinear diffusion problem),

$$
\hat{h}_{H}(\hat{x}, \hat{t})=\hat{t}^{-1 / 5}\left(\frac{3}{10}\left(\xi_{f}^{2}-\xi^{2}\right)\right)^{1 / 3},
$$

where the similarity variable is

$$
\xi=\frac{\hat{x}}{\hat{t}^{1 / 5}} \text { and } \xi_{f}=\hat{V}_{0}^{3 / 5}\left(\frac{\sqrt[3]{\frac{3}{10}} \sqrt{\pi} \Gamma\left(\frac{1}{3}\right)}{5 \Gamma\left(\frac{5}{6}\right)}\right)^{-3 / 5} \approx 1.411 \hat{V}_{0}^{3 / 5},
$$

where $\Gamma$ denotes the gamma function. Hereafter we use the superscript $H$ to refer to self-similar solution (5) derived by Huppert. ${ }^{34}$ The front position is denoted by

$$
\hat{x}_{H}(t)=\xi_{f} \hat{t}^{1 / 5}
$$

This solution sheds light on the flow behavior at sufficiently long times, i.e., after the influence of the initial conditions is no longer felt. At short times, the flow is influenced by inertia. The transition between the inertia-dominated and long-term viscous regimes depends on the flow Reynolds number and aspect ratio of the reservoir. ${ }^{40}$ Dimensional arguments ${ }^{34}$ show that the typical transition time during which the viscous and inertial forces are comparable is very short: $t_{t r} \sim\left(V_{0}^{4} g^{-2} v^{-3}\right)^{1 / 7}=O(0.1) \mathrm{s}$ for the experiments presented in Sec. IV. Earlier experiments carried out with highly viscous fluids confirm the relevance of this scaling. ${ }^{38}$

\section{Extension of Huppert's solution for stationary layers}

At time $t=t_{0}$, the flow front is about to enter the erodible domain, where a layer of fluid is held initially at rest behind a backwards step (see Fig. 2). The stationary fluid lies between $z=0$ and $z=B(x) \leq 0$, defining a rigid base below which entrainment is impossible. The bed-flow interface is denoted by $b(x, t)$ and as discussed above, this interface is an acceleration wave. Another material surface is of interest: the contact discontinuity $d(x, t)$ separates the fluid coming from the reservoir and that initially at rest (as we will see later, this interface can easily be tracked by using liquids of different color in the flow and bed).

We consider the entrainment process to be made up of two successive phases: as the stationary layer is initially at rest, there should be a short acceleration phase during which the bed material is set into motion by the incoming current. Once in motion, the fluid from the bed flows together with the fluid from the current in the total domain. During the acceleration phase, the kinematic boundary condition at the bottom is replaced with a jump condition along the acceleration wave $b(x, t)$

$$
\llbracket \boldsymbol{\sigma} \cdot \boldsymbol{n} \rrbracket=0,
$$

where $\llbracket \cdot \rrbracket$ denotes the jump of the total stress across the acceleration wave $b(x, t)$ oriented by the normal vector $\boldsymbol{n}$ ( $\boldsymbol{\sigma}$ is the total stress tensor). ${ }^{30}$ There is no pressure jump across this interface and so jump condition (8) expresses the balance between the shear stress and normal stresses on the surface $b(x, t)$. The no-slip condition also applies

$$
\boldsymbol{u} \cdot \boldsymbol{n}=0 .
$$

The system of governing equations - consisting of the Navier-Stokes equations subject to boundary conditions (8) and (9)-are too complicated to gain analytical traction. Yet, our guess is that the 
characteristic time $t_{c}$ associated with the acceleration phase is very short, typically $t_{c} \sim B_{*}^{2} / \nu$, where $B_{*}$ denotes the depth scale of the stationary layer. This time arises, for instance, in the Stokes' first problem (also called the Rayleigh problem), in which a sudden shear is applied to a quiescent Newtonian fluid, and the Blasius problem, in which the growth of the viscous boundary layer is studied. ${ }^{41}$ If we compare the typical time of viscous diffusion $t_{c}=B_{*}^{2} / v$ to the flow time scale $T_{*}=L_{*} / U_{*}$, we get

$$
\hat{t}_{c}=\frac{t_{c}}{T_{*}}=\epsilon^{5}\left(\frac{B_{*}}{H_{*}}\right)^{2} \frac{g L_{*}^{3}}{v^{2}} .
$$

In the experiments presented below, we have $\epsilon=O\left(10^{-2}\right)$ and $B_{*} / H_{*}=O(1)$ so that $\hat{t}_{c}=O\left(10^{-3}\right)$ (for $L_{*} \sim 1 \mathrm{~m}$ and $v \sim 10^{-3} \mathrm{~m}^{2} \mathrm{~s}^{-1}$ ), which means that $t_{c}$ is negligibly small compared to the typical flow time scale. This implies that the characteristic time of the setting into motion of the fluid is so short that the acceleration wave $b(x, t)$ reaches the fixed bottom $B(x)$ nearly instantaneously. In the stationary layer, the fluid is sheared and separates from the upstream end of the bed, while the space it creates is rapidly filled by the incoming current. In short, the first of the two processes happens so quickly that it can be ignored, and the second process becomes dominant.

We are now in position of extending Huppert's solution by considering that for $x_{\text {step }}<x<$ $x_{\text {step }}+\ell_{\text {bed }}$, the no-slip condition no longer applies on a solid boundary at $z=0$, but on the fixed bottom $z=B(x)$. The dimensionless velocity field is found to be

$$
\begin{aligned}
u(x, z, t) & =\frac{1}{2} \frac{\partial h}{\partial x}\left(z^{2}-2 h z-B^{2}+2 h B\right), \\
w(x, z, t) & =-\frac{1}{2}\left(\frac{\partial^{2} h}{\partial x^{2}}\left(\frac{z^{3}}{3}-h z^{2}+2 h B z-B^{2} z+\frac{2 B^{3}}{3}-h B^{2}\right)\right. \\
& \left.+\left(\frac{\partial h}{\partial x}\right)^{2}\left(2 B z-z^{2}-B^{2}\right)+\frac{\partial h}{\partial x} \frac{\partial B}{\partial x}\left(h z-B z+B^{2}-h B\right)\right),
\end{aligned}
$$

where the hats have been removed for the simplicity. Mass conservation implies that for $x_{\text {step }}<x<$ $x_{\text {step }}+\ell_{\text {bed }}$ the evolution equation for $h$ reads

$$
\frac{\partial h}{\partial t}-\frac{1}{3} \frac{\partial}{\partial x}\left(\frac{\partial h}{\partial x}(h(x, t)-B(x))^{3}\right)=0 .
$$

Naturally, setting $B=0$ leads to usual nonlinear diffusion equation (4). The total fluid in the system is conserved, i.e., the volume per unit width of the fluid released by the dam-break $\left(V_{0}\right)$ together with the bed fluid $\left(\ell_{\text {step }} \delta h\right)$. When fluid is displaced below $z=0$, this is balanced by fluid uplift downstream, advancing the front $x_{F}(t)$, as shown in Fig. 2. Thus conservation of fluid gives

$$
\int_{0}^{x_{F}(t)} h(x, t) d x=V_{0}
$$

where $x_{F}(t)$ is the value of $x$ at the front such that $h\left(x_{F}, t\right)=0$. The upwards forcing of the bed fluid means that $x_{F}$, the actual front, lies further downstream than $x_{H}$, the front position of the Huppert solution on a rigid bed in (7) (see Fig. 2).

An asymptotic solution to the problem was sought as the dimensionless Huppert solution plus a correction of order $\delta h=-B$ (the small depth of the bed), yet no solution was found that satisfied the no-flux boundary condition at $x=0$ whilst also remaining bounded in time. As the full analytical solution to this problem was not readily obtained, we looked to numerical methods. While final governing equation (12) is not dramatically different from that derived by Huppert, ${ }^{34}$ the changes mean that it is no longer possible to work with analytical solutions.

\section{Numerical solution}

The parabolic solver pdepe in MatLab was used to solve dimensionless problem (12) in order to make a comparison with the experimental results. Note that the Galerkin method ${ }^{42}$ used in this solver is unable to cope with shocks. We therefore smoothed the topography discontinuities at 
each end of the step by approximating the step as $B(x)=-\delta h / 2\left(\tanh \left(a\left(x-x_{\text {step }}\right)\right)-\tanh (a(x-\right.$ $\left.x_{\text {step }}-\ell_{\text {bed }}\right)$ )) where $a$ is a free parameter. In practice, setting $a=1000$ provided good results (for a mesh size $\Delta x=0.5 \mathrm{~mm}$, the thickness of the regularized step was $4 \mathrm{~mm}$, i.e., $8 \Delta x$ ). The function $B(x)$ was chosen to approximate the stepped base as smoothly as possible. Using no-flux boundary conditions at each end, we solved governing equation (12) for the flow depth. Then using Eq. (11), we determined the velocity field for $B<z<h(x, t)$.

Figures 3(a)-3(c) give examples of flow depth evolution for different stationary layer depths, while Fig. 3(d) shows the effect of the bed thickness $\delta h$ on front position. The position of the step was $x_{\text {step }}=50 \mathrm{~cm}$ and its length $\ell_{\text {bed }}=50 \mathrm{~cm}$. Initially, the fluid was contained in a reservoir of length $\ell_{\text {res }}=30 \mathrm{~cm}$ and the volume per unit width was $V_{0}=8 \times 10^{-3} \mathrm{~m}^{2}$. So the initial condition was $h=h_{0}=V_{0} / \ell_{\text {res }}$ for $0 \leq x \leq \ell_{\text {res }}$ and zero elsewhere. The length and depth scales were $L_{*}=1 \mathrm{~m}$ and $H_{*}=V_{0} / L_{*}=0.008 \mathrm{~m}$. The front position $x_{F}$ was determined numerically as the furthest point satisfying $h>\epsilon$ with $\epsilon=10^{-4} \mathrm{~m}(\epsilon=\Delta x / 5)$. For dry beds, front position did not depend on $\epsilon$, but for stationary layers, the change in the flow depth profile near the leading edge made the front position very sensitive to $\epsilon$.
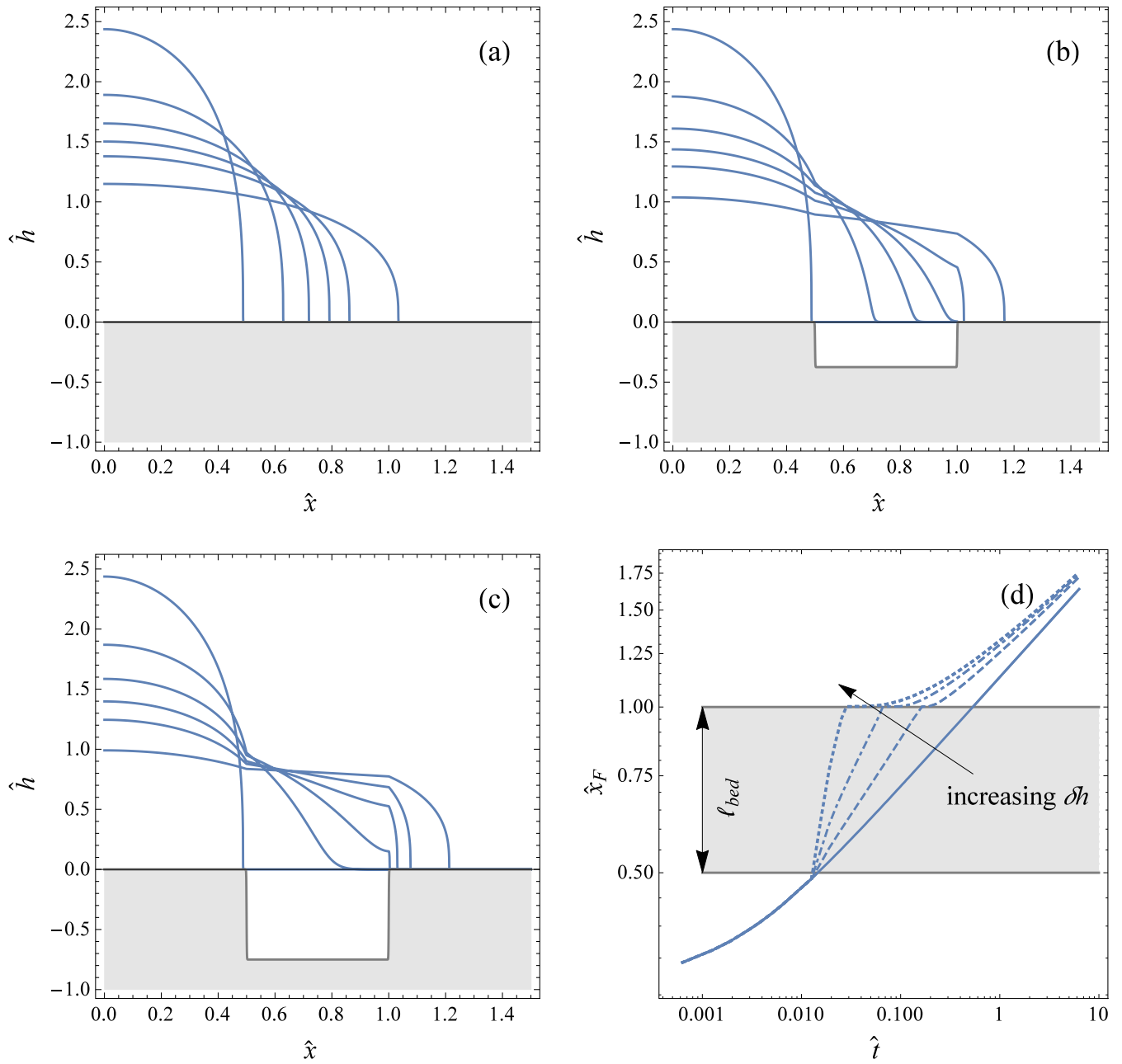

FIG. 3. Fluid collapse onto a stationary layer of length $\hat{\ell}_{\text {bed }}=0.5$. ((a)-(c)) Flow depth profiles with progression from $t=2 \mathrm{~s}$ to $t=100 \mathrm{~s}$ (from $\hat{t}=0.012$ to $\hat{t}=0.63$ dimensionless time). Profiles are plotted for $t=2 \mathrm{~s}, 8 \mathrm{~s}, 16 \mathrm{~s}, 26 \mathrm{~s}, 40 \mathrm{~s}$, and $100 \mathrm{~s}$ ( $\hat{t}=0.012,0.05,0.1,0.16,0.25$, and 0.63 in dimensionless time). (a) Bed depth $\delta \hat{h}=0$ (non-entrainment). (b) $\delta \hat{h}=0.375$ $(3 \mathrm{~mm})$. (c) $\delta \hat{h}=0.75(6 \mathrm{~mm})$. (d) Front position with time for different heights $\delta \hat{h}$ of the stationary layer: solid line $\delta \hat{h}=0$ (non-entrainment), dashed line $\delta \hat{h}=0.375$, dotted-dashed line $\delta \hat{h}=0.75$, dotted line $\delta \hat{h}=1.5$. The grey area indicates the stationary layer. Computations for a Newtonian fluid of viscosity $\mu=1 \mathrm{~Pa} \mathrm{~s}$ and density $\varrho=1257 \mathrm{~kg} \mathrm{~m}^{-3}$. 
Several features emerge from Fig. 3. The first noticeable difference among the numerical solutions to Eq. (12) with or without entrainment is the change in the flow depth profile. In the solution for the no-entrainment case [see Fig. 3(a)], the head takes the form of a blunt nose whereas for eroding flows, the head makes an acute angle with the bed surface. The second feature is that the flow travels more quickly when it can entrain loose material. This can be anticipated if we consider that the incoming flow slips along the bed surface and so can reach higher velocities than non-eroding flows. Yet, the process is more complicated than this simple picture because front acceleration depends on the stationary layer depth $\delta h$, as shown by Fig. 3(d). A more subtle feature is the existence of waiting time solutions when the head approaches the stationary layer's downstream limit: the flow forms an acute wedge-shaped leading edge until it reaches the end. Then the front comes to a halt, while the fluid behind it continues to flow. The front steepens, and eventually resumes its motion. This behavior can be expected since it is typical of the diffusive behavior of viscous films with an acute leading edge. ${ }^{4-45}$ Figure 3(d) reveals that basal entrainment causes the leading edge to stretch rapidly. Front acceleration is vigorous, and its strength depends on the stationary layer depth $\delta h$. Yet, there is also a vigorous deceleration once the front has passed the stationary layer's rightmost end. At long times, there is little difference between solutions with and without entrainment, and still less when the stationary layer increases in depth. So, in that case, the local effects of basal entrainment on the flow dynamics are much more pronounced than the global effects.

\section{EXPERIMENTAL FACILITY AND PROTOCOL}

\section{A. Experimental method and equipment}

A $3.5 \mathrm{~m}$ long by $10 \mathrm{~cm}$ wide inclinable flume was used for the experiments. The flume was made with a poly(methyl methacrylate) (PMMA) base and had a $50 \mathrm{~cm}$ long viewing window on each side. The observation area was fixed, so for this article a mobile pneumatic lock-gate was added in order to release the material at the appropriate distance. Two shallow sheets of PMMA were placed horizontally along the flume bottom and separated by a gap filled with fluid, so that the dam-break current initially flowed over a rigid base, then over a finite layer of loose material — the stationary layer-before continuing over a rigid base (see Fig. 4). The flume inclination was set to $0^{\circ}$.

A $2 \mathrm{~W}$ Diode-Pumped Solid State Nd:YAG laser with wavelength $532 \mathrm{~nm}$ was used with the optical setup shown in Fig. 5 to create a vertical laser sheet down the center of the flume in the observation zone, so that particle image velocimetry (PIV) could be performed. PIV is a flow visualization technique in which a seeded flow is filmed at high speed so that the instantaneous velocities can be found by comparing the distribution of seeds in two consecutive images. ${ }^{46}$ The seeds used in this study were $20 \mu \mathrm{m}$ polyamide beads tagged with rhodamine $6 \mathrm{G}$, a stain which is fluorescent in

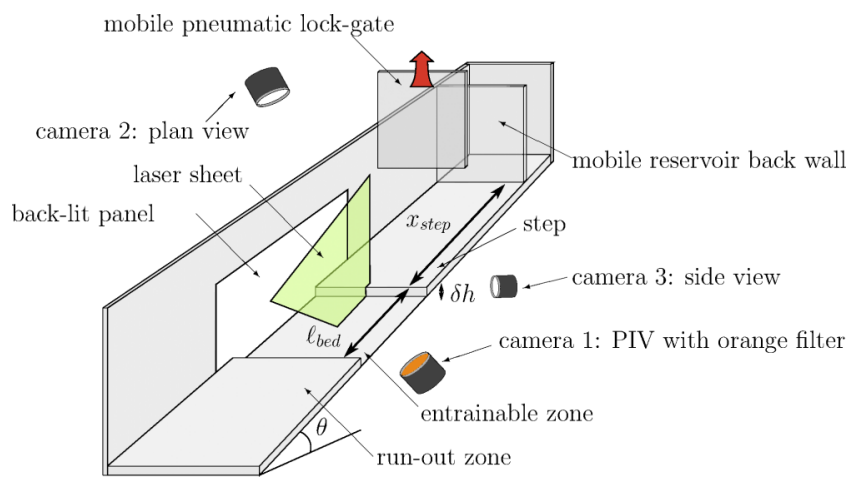

FIG. 4. Experimental setup including reservoir, lock-gate, step and stationary layer, and the location of the laser sheet. The flume inclination is $\theta=0^{\circ}$, and the bed dimensions are $\ell_{\text {bed }}$ long by $\delta h$ deep. 


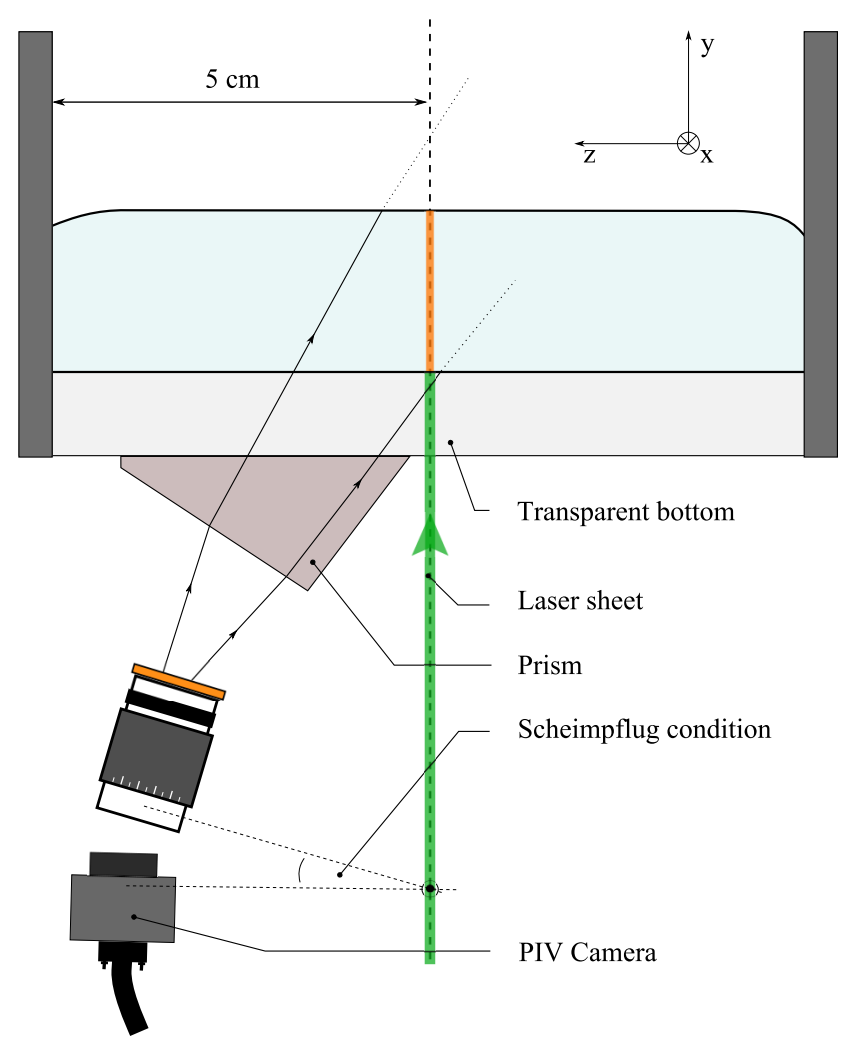

FIG. 5. Sketch of the measurement system for the velocity profiles within the moving fluid. Because of the fluid/air interface and the three-dimensional nature of the flows, we were forced to film the flow from below. When shooting images with a camera whose sensor (CCD) is not parallel with the object, one can use the Scheimpflug principle, which involves tilting the camera until the image plane (on the CCD), the lens plane, and the object plane (lit by the laser sheet) have a common line of intersection.

green light. In this way only the particles in the central laser sheet were illuminated and only they were filmed.

Three different high-speed cameras were used in the experiments. Camera 1 filmed the illuminated internal section of the flow through an orange filter: the light emitted by rhodamine had a longer wavelength than that absorbed and the orange filter blocked the green light of the laser but allowed the transmission of the emitted light. This camera was placed below the flume and filmed through the transparent base and a prism, using a tilted lens for the Scheimpflug principle ${ }^{46}$ in order to obtain clear images from a focal plane which was non-parallel to the image plane. Usually PIV is performed by filming from the side, but the flow front in many of our experiments was significantly curved in the cross-stream direction, and so images were acquired through the base to avoid distortion at the flow front.

Camera 1 was a Basler A403kc camera, and was calibrated for each experiment using a grid immersed in fluid in the flume. PIV measurements were taken in a $6.5-\mathrm{cm}$ long central streamwise section in the entrainment zone. Camera 2 (also a Basler A403k) filmed from above to show the progression of the flow front, through a red filter if the laser was on. Camera 3 was used to film through the observation panel in the side of the flume in order to obtain the flow and bed surface elevation during entrainment. This was a Basler acA2000-165um USB 3.0 camera. A LED panel provided backlighting.

To obtain measurements from camera 1's images, we employed the velocity field calculated using PIV between two images an appropriate time-step apart. This was then filtered with a signal to noise ratio (SNR) of 1.3 and a local filter of 2.7 , then all removed vectors were interpolated linearly. All measurements were corrected for perspective using a calibration grid. The PIV software used was the open source package MatPIV. ${ }^{47}$ Strong velocity gradients reduce measurement 
accuracy, ${ }^{48}$ so steps were taken to minimize errors, such as choosing the optimum seeding density and correlation window size. See the Appendix for uncertainties on the measurements.

\section{B. Newtonian fluids}

The experiments were carried out using glycerol (supplied by Alfa Aesar GmbH, Germany) diluted to a $98.5 \%$ volume concentration aqueous solution for the first experimental campaign. This was done because glycerol has a high affinity for water, and is unstable at high concentrations, absorbing water vapour quickly from its surroundings. At this concentration, its density is $1257.5 \mathrm{~kg} \mathrm{~m}^{-3} \pm 0.5 \mathrm{~kg} \mathrm{~m}^{-3}$. As glycerol has a highly variable viscosity with temperature and concentration, its viscosity was closely monitored and experiments were performed as close to $20{ }^{\circ} \mathrm{C}$ as possible.

Three experimental campaigns were undertaken (see Tables I and II). For campaign A, the fluid was dyed with methylene blue and filmed from above over the entire flow length, and through the $50 \mathrm{~cm}$ long transparent side-panels, in order to obtain information about the bulk flow characteristics, namely, the front position with time and the flow depth profile during entrainment. In campaign $\mathrm{B}$, the flow was seeded and filmed for PIV at the entry to the entrainment zone, in order to study the internal dynamics of interaction between the incoming flow and the bed. Campaign $\mathrm{C}$ was devised to determine the influence of inertia on the front propagation: to this end, larger volumes of fluid were used. The experiments are detailed in Table II. In these experiments, we could no longer use the transparent side panels, as the stationary layer was much longer and further downstream. Instead the fluid was mixed with titanium dioxide powder so that it became white, and a red laser sheet was projected diagonally from the flume side onto the flume bottom, so that over the stationary layer, the front position could be estimated by looking at how the laser position moved.

The reservoir length $\ell_{\text {res }}$ was kept constant at $30 \mathrm{~cm}$ for most experiments of campaign A, and $50 \mathrm{~cm}$ for campaign C; only in the two runs A9 and A10 in which $1500 \mathrm{ml}$ fluid was released was the reservoir the shorter length of $20 \mathrm{~cm}$. Taking inspiration from Didden and Maxworthy, ${ }^{36}$ we chose $x_{\text {step }}$ so that $x_{\text {step }} \gg\left(\varrho^{2} g V_{0}^{5} / \mu^{2}\right)^{1 / 7}$, where $V_{0}$ is the volume per unit width. This guaranteed a dominant balance between gravity and viscous forces, with inertia playing a less significant role. As $x_{\text {step }}$ is the distance from the reservoir back wall to the step, it also includes the length of the reservoir. The length of the stationary layer $\ell_{\text {bed }}$ was varied between 10 and $100 \mathrm{~cm}$, and its depth was either $3,6,9$, or $12 \mathrm{~mm}$.

TABLE I. Features of the experiments performed using glycerol for campaigns A and B: $V$ initial volume released, $\ell_{\text {res }}$ length of the reservoir, $x_{\text {step }}$ position of the step (stationary layer), $\ell_{\text {bed }}$ length of the stationary layer, $\delta h$ bed depth, $\mu$ dynamic viscosity, $H_{*}$ flow depth scale, $\epsilon$ aspect ratio, $U_{*}$ velocity scale, $R e$ flow Reynolds number. The length scale was set to $L_{*}=1 \mathrm{~m}$ for non-eroding flows and $L_{*}=x_{\text {step }}$ for eroding flows.

\begin{tabular}{|c|c|c|c|c|c|c|c|c|c|c|c|}
\hline Run & $\begin{array}{c}V \\
(\mathrm{ml})\end{array}$ & $\begin{array}{l}\ell_{r e s} \\
(\mathrm{~cm})\end{array}$ & $\begin{array}{l}x_{\text {step }} \\
(\mathrm{cm})\end{array}$ & $\begin{array}{c}\delta h \\
(\mathrm{~mm})\end{array}$ & $\begin{array}{l}\ell_{\text {bed }} \\
(\mathrm{cm})\end{array}$ & $\begin{array}{c}\varrho \\
\left(\mathrm{kg} \mathrm{m}^{-3}\right)\end{array}$ & $\begin{array}{c}\mu \\
(\mathrm{Pa} \mathrm{s})\end{array}$ & $\begin{array}{c}H_{*} \\
(\mathrm{~cm})\end{array}$ & $\epsilon$ & $\begin{array}{c}U_{*} \\
\left(\mathrm{~cm} \mathrm{~s}^{-1}\right)\end{array}$ & $R e$ \\
\hline A1 & 800 & 30 & $\ldots$ & $\ldots$ & $\ldots$ & 1257 & 1.041 & 0.8 & 0.008 & 0.6 & 6 \\
\hline $\mathrm{A} 2$ & 800 & 30 & 50 & 3 & 50 & 1257 & 0.916 & 1.6 & 0.032 & 11.0 & 2 \\
\hline A 3 & 800 & 30 & 50 & 6 & 50 & 1257 & 1.038 & 1.6 & 0.032 & 9.7 & 2 \\
\hline A4 & 800 & 30 & 50 & 9 & 50 & 1257 & 0.902 & 1.6 & 0.032 & 11.2 & 2 \\
\hline A5 & 800 & 30 & 50 & 6 & 30 & 1257 & 1.007 & 1.6 & 0.032 & 10.0 & 2 \\
\hline A6 & 800 & 30 & 50 & 6 & 10 & 1257 & 1.009 & 1.6 & 0.032 & 10.0 & 2 \\
\hline A7 & 800 & 30 & 60 & 6 & 30 & 1257 & 1.011 & 1.3 & 0.022 & 4.8 & 1 \\
\hline A8 & 800 & 30 & 70 & 6 & 30 & 1257 & 0.984 & 1.1 & 0.016 & 2.7 & 0.4 \\
\hline A9 & 1500 & 20 & $\ldots$ & $\ldots$ & $\ldots$ & 1257 & 0.843 & 1.5 & 0.015 & 4.9 & 1 \\
\hline A10 & 1500 & 20 & 60 & 6 & 50 & 1257 & 0.835 & 2.5 & 0.042 & 38.5 & 14 \\
\hline B1 & 800 & 30 & 50 & 3 & 50 & 1257 & 1.121 & 1.6 & 0.032 & 9.0 & 2 \\
\hline B2 & 800 & 30 & 50 & 6 & 50 & 1257 & 1.121 & 1.6 & 0.032 & 9.0 & 2 \\
\hline
\end{tabular}


TABLE II. Features of the experiments performed using glycerol for campaign C: $V$ initial volume released, $\ell_{\text {res }}$ length of the reservoir, $x_{\text {step }}$ position of the step (stationary layer), $\ell_{b e d}$ length of the stationary layer, $\delta h$ bed depth, $\mu$ dynamic viscosity, $H_{*}$ flow depth scale, $\epsilon$ aspect ratio, $U_{*}$ velocity scale, $R e$ flow Reynolds number.

\begin{tabular}{lccccccccrrr}
\hline \hline Run & $\begin{array}{c}V \\
(\mathrm{ml})\end{array}$ & $\begin{array}{c}\ell_{\text {res }} \\
(\mathrm{cm})\end{array}$ & $\begin{array}{c}x_{\text {step }} \\
(\mathrm{cm})\end{array}$ & $\begin{array}{c}\delta h \\
(\mathrm{~mm})\end{array}$ & $\begin{array}{c}\ell_{\text {bed }} \\
(\mathrm{cm})\end{array}$ & $\begin{array}{c}\varrho \\
\left(\mathrm{kg} \mathrm{m}^{-3}\right)\end{array}$ & $\begin{array}{c}\mu \\
(\mathrm{Pa} \mathrm{s})\end{array}$ & $\begin{array}{c}H_{*} \\
(\mathrm{~cm})\end{array}$ & $\epsilon$ & $\begin{array}{c}U_{*} \\
\left(\mathrm{~cm} \mathrm{~s}^{-1}\right)\end{array}$ & $R e$ \\
\hline $\mathrm{C} 1$ & 3200 & 50 & $\ldots$ & 0 & $\ldots$ & 1252 & 0.535 & 3.2 & 0.032 & 75.2 & 56 \\
$\mathrm{C} 2$ & 4800 & 50 & $\ldots$ & 0 & $\ldots$ & 1252 & 0.525 & 4.8 & 0.048 & 258.7 & 296 \\
$\mathrm{C} 3$ & 4800 & 50 & 140 & 12 & 100 & 1252 & 0.509 & 3.4 & 0.024 & 69.5 & 59 \\
$\mathrm{C} 4$ & 3200 & 50 & 140 & 12 & 100 & 1252 & 0.497 & 2.3 & 0.016 & 21.1 & 12 \\
C5 & 3200 & 50 & 140 & 6 & 100 & 1252 & 0.485 & 2.3 & 0.016 & 21.6 & 13 \\
C6 & 4800 & 50 & 140 & 6 & 100 & 1252 & 0.480 & 3.4 & 0.024 & 73.7 & 66 \\
C7 & 4800 & 50 & 140 & 3 & 100 & 1252 & 0.475 & 3.4 & 0.024 & 74.4 & 67 \\
C8 & 3200 & 50 & 140 & 3 & 100 & 1248 & 0.468 & 2.3 & 0.016 & 22.3 & 14 \\
C9 & 4800 & 50 & 140 & 3 & 50 & 1248 & 0.461 & 3.4 & 0.024 & 76.5 & 71 \\
C10 & 3200 & 50 & 140 & 3 & 50 & 1248 & 0.452 & 2.3 & 0.016 & 23.1 & 15 \\
C11 & 3200 & 50 & 140 & 12 & 50 & 1248 & 0.443 & 2.3 & 0.016 & 23.6 & 15 \\
C12 & 4800 & 50 & 140 & 12 & 50 & 1248 & 0.436 & 3.4 & 0.024 & 80.8 & 79 \\
C13 & 4800 & 50 & 140 & 6 & 50 & 1248 & 0.429 & 3.4 & 0.024 & 82.2 & 82 \\
C14 & 3200 & 50 & 140 & 6 & 50 & 1248 & 0.423 & 2.3 & 0.016 & 24.7 & 17 \\
C15 & 3200 & 50 & 231 & 6 & 50 & 1248 & 0.417 & 1.4 & 0.006 & 3.4 & 1 \\
C16 & 4800 & 50 & 231 & 6 & 50 & 1248 & 0.413 & 2.1 & 0.009 & 11.5 & 7 \\
C17 & 4800 & 50 & 231 & 12 & 50 & 1248 & 0.409 & 2.1 & 0.009 & 11.6 & 7 \\
C18 & 3200 & 50 & 231 & 12 & 50 & 1248 & 0.406 & 1.4 & 0.006 & 3.5 & 1 \\
C19 & 3200 & 50 & 231 & 3 & 50 & 1248 & 0.403 & 1.4 & 0.006 & 3.5 & 1 \\
C20 & 4800 & 50 & 231 & 3 & 50 & 1245 & 0.397 & 2.1 & 0.009 & 11.9 & 8 \\
\hline \hline
\end{tabular}

For campaigns $\mathrm{A}$ and $\mathrm{C}$, both the bed and the reservoir fluids were dyed the same color, but for campaign B, two configurations were used for visualizing the flow. In a "reservoir run," the fluid released from the reservoir was seeded and the bed fluid was largely without seeds. The idea here was to show a clear and measurable interface (the contact discontinuity $d(x, t)$ in Figs. 1 and 6 (Multimedia view)) between the substrate and the avalanche. A "combined run" (where all fluid was seeded) provides detailed velocity measurements in all of the system, but the interface is not shown. The reader is referred to an earlier publication ${ }^{49}$ detailing the tracking of the contact discontinuity $d(x, t)$. The reader can see the online video from which Fig. 6 (Multimedia view) was extracted. In practice, it was easier to track the contact discontinuity surface $d(x, t)$ than the acceleration wave $b(x, t)$ : as shown in the video, the acceleration wave propagated quickly, but its was associated with minute changes in the fluid velocity, which were barely detected by our system.

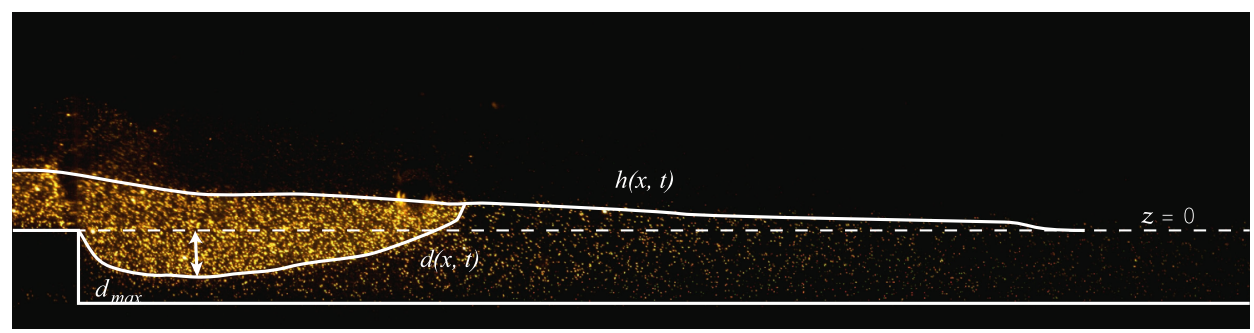

FIG. 6. Raw image for the "reservoir run" configuration. The flow boundaries are highlighted. The incoming fluid is seeded with polyamide microbeads tagged with rhodamine 6G. A vertical laser sheet lightens the flow and stationary layer. The contact discontinuity $d(x, t)$ is a material surface that deforms continuously with incoming fluid. As the image was taken from below using the Scheimpflug principle (see Fig. 5), part of the flow behind the lit vertical plane is seen on the image. (Multimedia view) [URL: http://dx.doi.org/10.1063/1.4947242.1] 


\section{EXPERIMENTAL RESULTS}

\section{A. Front position}

We begin by analyzing the experiments performed to investigate the bulk dynamics of entraining gravity-driven flows. The flow depth profile $h(x, t)$ and the flow front position $x_{F}(t)$ were studied, and compared with numerical solutions to extended Huppert's model (12).

In Fig. 7 the flow front is plotted with time for campaign A. The most influential parameter is the length of the stationary layer $\ell_{\text {bed }}$ as the front position is significantly increased with increasing
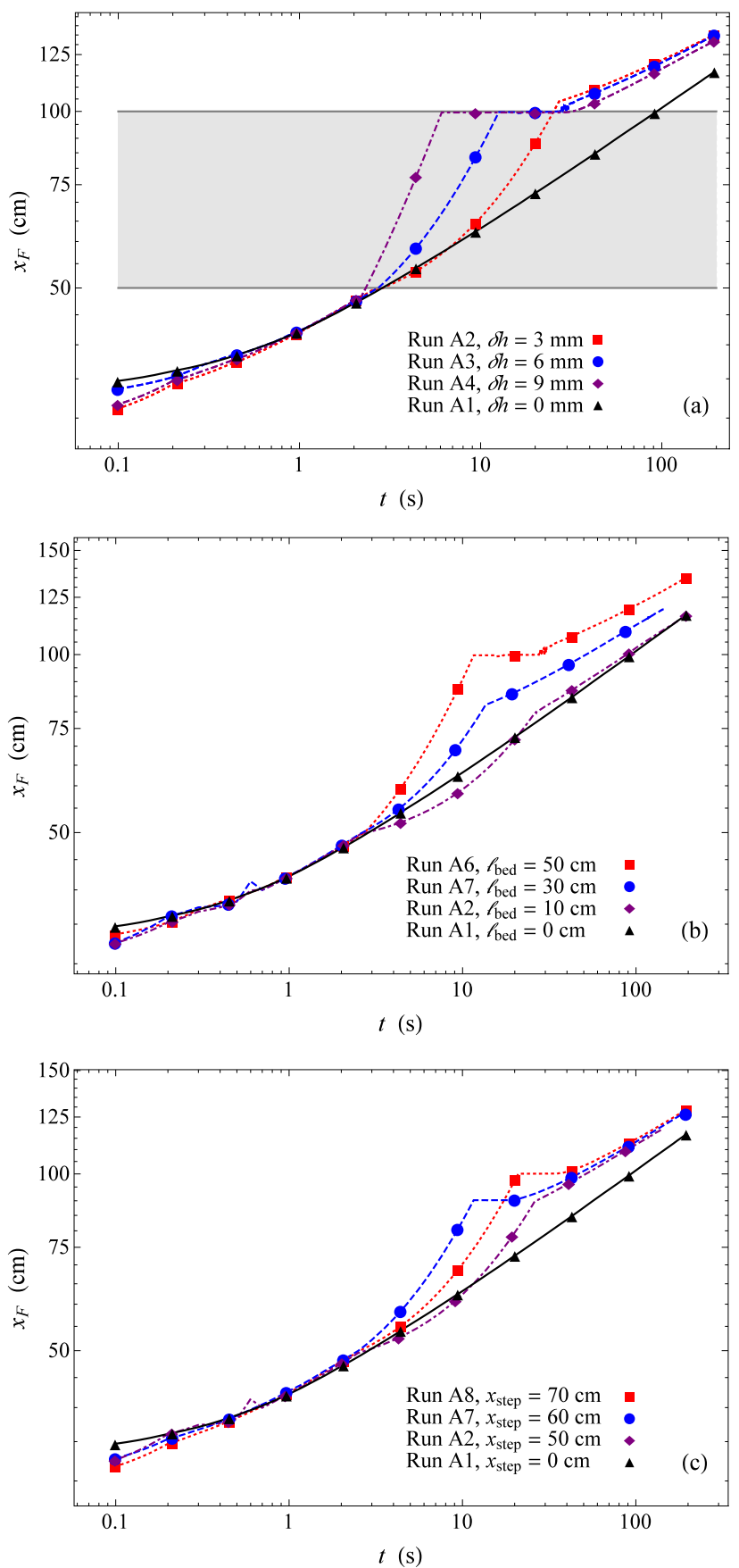

FIG. 7. Front position against time: (a) effect of the stationary layer depth $\delta h$; (b) effect of the bed length $\ell_{\text {step }}$; (c) effect of the stationary layer location $x_{\text {step }}$. In panel (a), the grey area indicates the stationary layer. 


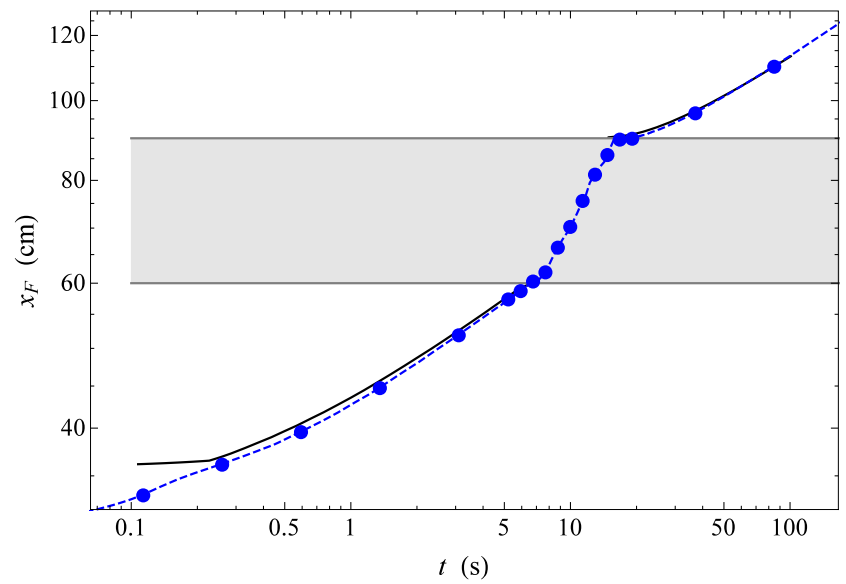

FIG. 8. Comparing the numerical and experimental results for front progression in experiment A7: the dashed line marked with dots shows the experimental measurements, while the solid line represents the numerical solution to extended Huppert's equation (12). The grey area indicates the stationary layer.

$\ell_{\text {bed }}$ [see Fig. 7(b)]. The bed depth $\delta h$ has a small effect [see Fig. 7(a)]: we retrieve the behavior exhibited by numerical simulations [see Fig. 3(d)] with a vigorous acceleration controlled by the bed depth, followed by a deceleration with, at long times, little difference between the different curves. The position of the bed has no significant effect within the range considered in the long term as the curves collapse on the same curve at long times [see Fig. 7(c)].

Figure 8 shows the (dimensional) front position with time for run A7. A numerical simulation was performed and the front position was identified as the furthest point downstream with $h>10^{-4} \mathrm{~m}$ (this was slightly lower than the resolution of camera 3 used for tracking the front). The comparison shows a close agreement over the entire domain-before the front reaches the stationary layer, while the front passes over the bed and after the front has left the bed-thus showing that the extended Huppert's model performs well at low Reynolds numbers.

How the basal entrainment affects front position can be explained using two arguments: a current on a higher step has extra gravitational potential energy when it sinks into the bed and it pushes downstream fluid upwards; and the increased distance between the current and the base leads to reduced friction at $z=0$ over the length of the stationary layer. The first factor enhances the front position whilst it travels over the stationary layer, but this is expected to be reversed when the front exits the erodible region over the forward step. The second factor must thus play an important role in flow evolution.

\section{B. Flow depth}

Figure 9 shows the flow depth profiles at time intervals of $6 \mathrm{~s}$ for a non-entraining and an entraining dam-break waves (runs A1 and A7, respectively). When the flow first contacts the stationary layer, the flow depth profile is composed of the original dam-break wave plus the initially flat surface of the stationary layer. The mobility of the bed then allows the discontinuity at the front to be quickly smoothed out in a diffusive way. For example, comparing experiment A7 with experiment A1 in Fig. 9 shows the significant influence of the stationary layer on the flow depth profile. This is in agreement with the numerical results of Fig. 3. Further, there is a kink in the surface just downstream of the step, which connects the incoming dam-break wave with the flow over the stationary layer at all times (this kink can be defined as a local curvature maximum). This shows that after the material has moved out onto the stationary layer, it flows away faster than the supplying gravity-driven flow.

When the flow front reaches the end of the stationary layer, it is seen to slow down significantly and even stop while the surface elevation increases (causing a significant change in the shape of the leading edge), before flowing over the rigid base once more. Examining the side-view images, it 

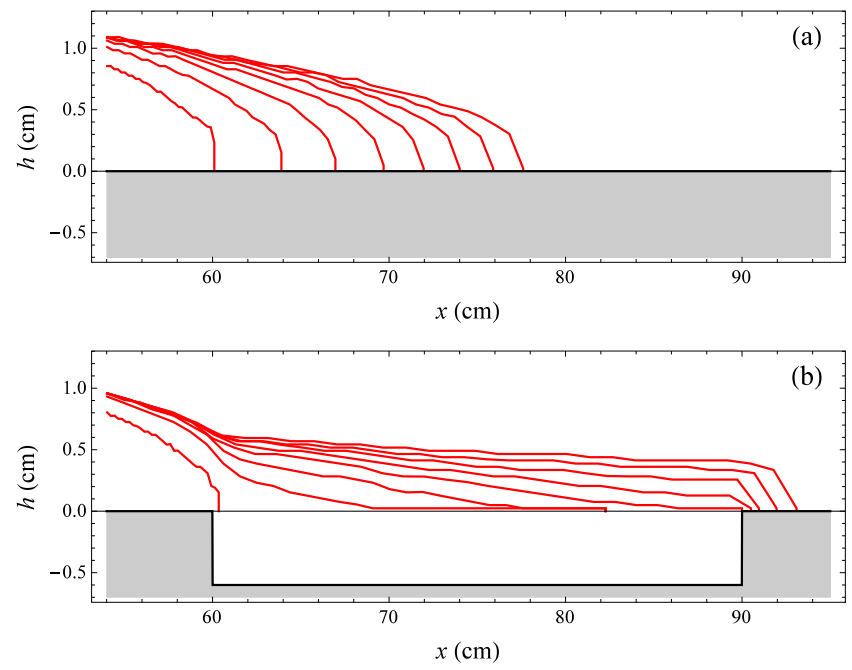

FIG. 9. Flow depth profile (measurements taken at 6-s intervals). (a) Run A1 (no entrainment). (b) Run A7 (with entrainment). The initial profile was taken at the same time $t_{0}$ (corresponding to the contact of the front with the stationary layer).

seems that the leading edge must steepen before the flow front is able to exit the erodible zone. This phenomenon recalls the waiting-time behavior observed during the spread of viscous films with an acute edge. ${ }^{43-45}$ This is again in agreement with the numerical simulations presented in Sec. II D.

Figure 10 shows the flow depth profiles for experiment A7. Both experimental and computational data are reported. The numerical solution to extended Huppert's model (12) captures the flow depth profile well. As it initially flows along the rigid bed, it is a non-entraining gravity current. When the flow front arrives at the step, it meets the erodible material, and two important flow changes occur. First, the current is no longer subject to the no-slip condition at $z=0$ in this region, instead this now applies at $z=-\delta h$. Second, as the flow front makes contact with the bed surface, there is no longer a contact line between the fluid and the rigid surface. Instead, the flow front contacts the bed surface, creating a flow depth profile extending to the end of the stationary layer, but which is initially zero downstream of the flow front.

When the flow front reaches the end of the bed, the flow depth increases until it is a few millimeters high before it continues to flow over the rigid base. As no surface tension has been considered, the model's good reproduction of this bulging behavior means that it can be attributed to the viscosity of the fluid alone, which controls the velocity gradient. The front must again travel over a rigid base, with zero velocity at $z=0$ and so the surface must be a certain elevation for it to flow at a detectable velocity.

\section{Internal velocity field}

The bed fluid was set into motion almost instantaneously when the flow front made contact with its surface. The motion was predominantly due to streamwise shear as the horizontal

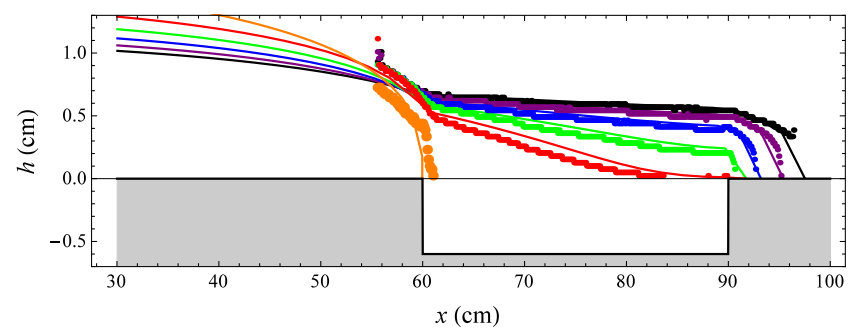

FIG. 10. Flow depth profiles for run A7 every $6 \mathrm{~s}$ from $t=0 \mathrm{~s}$ to $t=36 \mathrm{~s}$. The dots show the experimental data, while the solid lines represent the numerical solution to nonlinear diffusion equation (12). 
velocity in the front was greater than the vertical velocity. After the bed fluid was set into motion, the current sank downwards near the step to replace the material that had been advected downstream, explaining the convex shape of the contact discontinuity that we observed in our experiments (see Fig. 6 (Multimedia view)). Using the "reservoir runs" (see Sec. III B), it was possible to study the progression of the current as it flowed across the stationary layer surface, by measuring the position of the flow parameters $d_{\max }(t)$ (the maximum depth of the contact discontinuity wave $d$ ). During the acceleration phase, $d_{\max }$ increased rapidly with $t$, then its progression slowed, and finally it tended towards a constant value $\delta h$, when the rigid base stopped any further displacement from occurring. The progression of $d_{\max }$ can be fitted by the powerlaw function $\hat{d}_{\max }(t)=A_{i} \hat{t}^{B_{i}}+C_{i}$ where $\left\{A_{3}, B_{3}, C_{3}\right\}=\{-0.007,-0.573,0.186\}$ and $\left\{A_{6}, B_{6}, C_{6}\right\}=$ $\{-0.0155,-0.6,0.334\}$ for $3-\mathrm{mm}$ - and 6 -mm deep beds. This confirms that the acceleration phase during which an acceleration wave propagated across the stationary layer was very short. The typical duration ws $\hat{t}_{c}=O(0.01)$ (i.e., $0.1 \mathrm{~s}$ in dimensional time).

In Fig. 11, the velocity components $(\hat{u}, \hat{w})$ at $\Delta t=1 \mathrm{~s}(1 \mathrm{~s}$ after entry into the stationary layer $)$ found from run $\mathrm{B} 2$, are shown as contours and a vector field. The time $\Delta t=1 \mathrm{~s}$ corresponded to the end of the second phase (long-time behavior). The motion was predominantly horizontal, as shown by the vectors in the velocity field. The horizontal velocity $\hat{u}$ was strongest just above the step. For run B2 (experiment with the deeper bed), the flow was faster than for run B1, and fluid was in motion farther downstream after the same amount of time. For vertical velocity, the deeper bed also induced stronger velocities, but it is more enlightening to look at the direction of the flow. Near the flow front some regions of positive $\hat{w}$ were found, indicated by red arrows, which showed that when the incoming flow penetrated into the stationary layer, it induced uplift of bed material further downstream. This explains why, if the flow front $x_{F}(t)$ was defined as the furthest point downstream with $h(x, t)>0$, it was further downstream than the front of the non-entraining flow $x_{H}(t)$. Note there was a stagnant corner next to the step where there was no visible flow (as the fluid was Newtonian, this corner was likely to be occupied by viscous eddies, whose velocities were barely detectable during our experiments). Simulations (not shown here) showed that during entrainment, the horizontal velocity was strongest above the step and decreased downstream and that there was a region of upwards motion near the flow front. This is in agreement with the velocity fields obtained from experiments after the same amount of time.
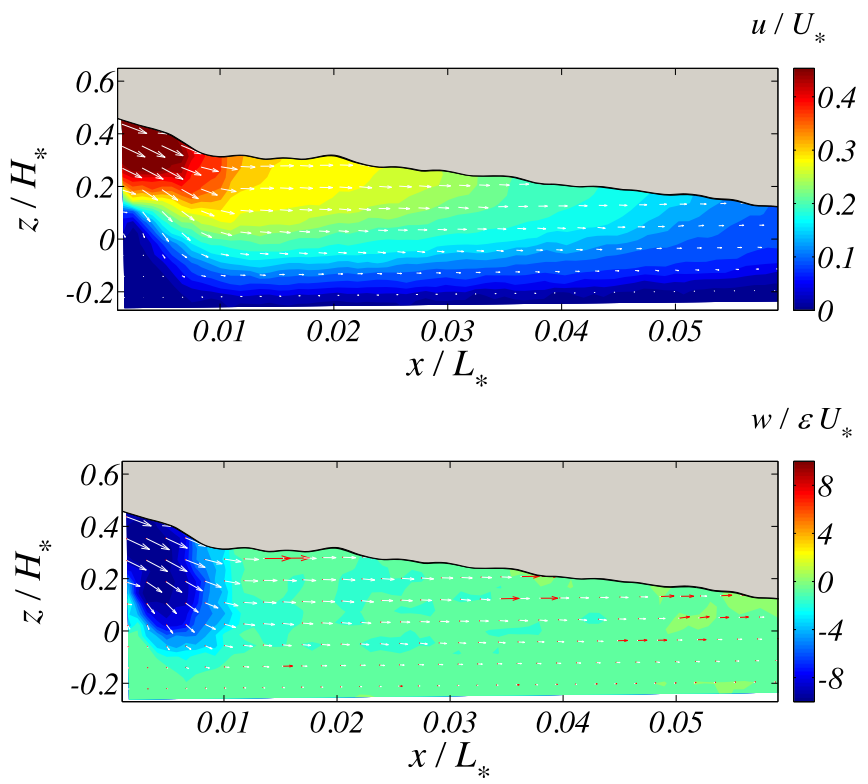

FIG. 11. Velocity fields for horizontal and vertical velocities after $1 \mathrm{~s}$ with velocity vectors for a 6-mm deep stationary layer (run B2). In the vertical velocity plot, the positive velocity vectors are highlighted in red. 


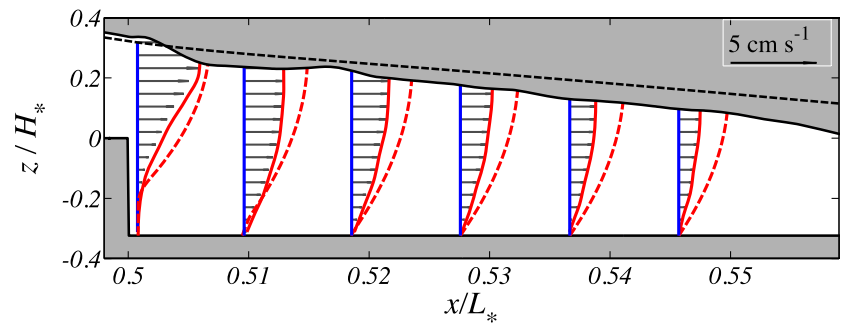

FIG. 12. Velocity profiles in $6 \mathrm{~mm}$ deep bed, after $1 \mathrm{~s}$ flow (run B2): comparison between PIV measurements (solid lines and arrows) and model predictions (dashed lines).

Figure 12 shows the horizontal velocity profiles, which are typical of viscous fluids, except for next to the step, where the velocity profile has a concave shape. Fluid in this corner was not entrained or replaced by incoming fluid. The modelled internal flow features are compared with the results from the experiments performed. The velocities are quantitatively similar to those observed: the velocity magnitude and the shape of the profiles resemble the predictions. Near the step the model performs well. Further downstream, the flow depth is overestimated, and thus the velocities
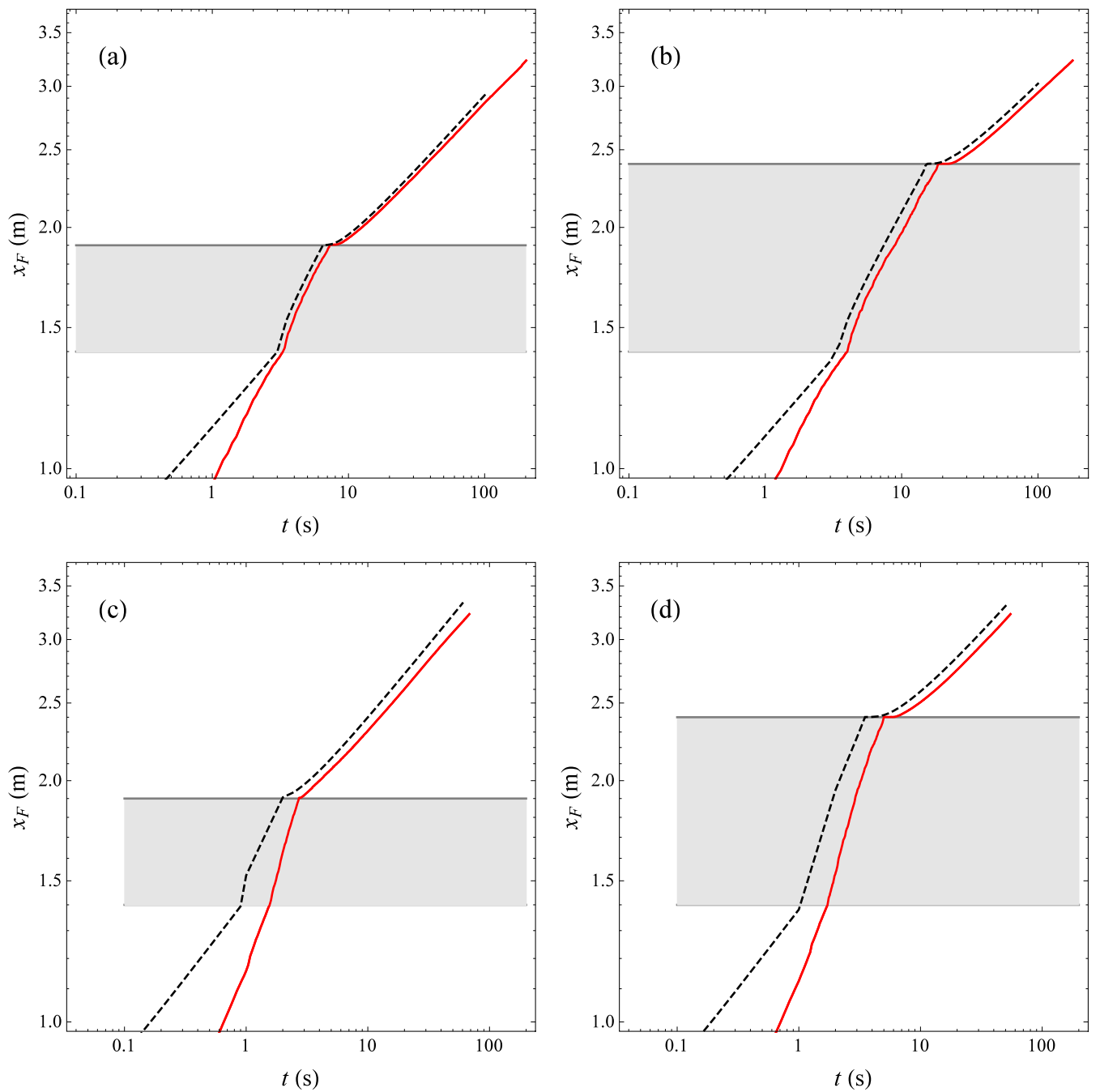

FIG. 13. Front position with time. (a) Run $\mathrm{C} 14, R e=14$. (b) Run C5, $R e=13$. (c) Run C3, $R e=59$. (d) Run C12, $R e=79$. Dashed line: numerical solution to Eq. (12). Solid line: experimental data. 
are overestimated, yet the predicted values are well within the same order of magnitude as the measurements. Note that for Newtonian flows under nonuniform flow conditions, the discrepancy between theory and experiment reaches the same order of magnitude. ${ }^{50}$ The most likely reason for this is the great sensitivity of $u$ to errors in the computation of $h$ and $\partial_{x} h$.

\section{Inertial effects}

Comparing the modelled front position with the front position found from experiments, we are able to infer some limitations of the model. Figure 13 shows the front position with time for Reynolds numbers ranging from 13 to 79. The comparison with run A7 [see Fig. 8] shows that the earlier stages of front propagation were very sensitive to the Reynolds number. For $R e$ close to unity, the extended Huppert's model captures front position from the earliest times (after the gate opening) to the longest. For $R e=O(10)$, the numerical solution to Eq. (12) slightly overestimates front position until the front reached the stationary layer. Then, there is a decent agreement between the experimental and numerical data with a deviation that does not exceed a few percent [see Figs. 13(a) and 13(b)]. At larger Reynolds numbers, the deviation further increases between the experimental data and the numerical solution. The gap is reduced at long times once the front has passed the downstream end of the stationary layer. While the deviation between data and simulation is noticeable in Figs. 13(c) and 13(d) at short and intermediate times, the lag time between these remains short (typically less than $1 \mathrm{~s}$ ).

\section{CONCLUSION}

This paper presents a simplified analysis of the mechanisms and effects of basal entrainment by laminar gravity-driven flows. The motivation was the highly complex problem of basal entrainment by geophysical flows such as avalanches and debris flows. A simple theoretical model was derived from the Navier-Stokes equations within the framework of lubrication theory. This was permitted as the time scale for the acceleration of the bed material from rest was found to be very short (typically $0.1 \mathrm{~s}$ in our experiments). Mass conservation was used to form evolution equation (12). The resulting system was similar to that of Huppert ${ }^{34}$ with a correction due to a shallow stationary layer below $z=0$. The problem was not analytically tractable, and so, in order to compare it with our experimental results, we computed the flow depth and internal velocities by solving Eqs. (12) and (11) numerically.

Dam-break experiments were devised, in which a viscous dam-break flow was generated by the sudden release of a fixed volume of fluid along a horizontal boundary. The bottom first comprised a rigid base and then a bed of erodible material (the same material as the fluid in the flow). When the released current made contact with the surface of the shallow stationary layer for the first time, it almost instantaneously accelerated the bed fluid from rest. Afterwards, the current flowed under gravity down the step, displacing the bed fluid downstream, and forcing some downstream fluid upwards, thus advancing the flow front. In this way the front position underwent a permanent increase after entrainment compared to the no-entrainment case. Yet, as soon as the front had reached the end of the stationary layer, it underwent a vigorous deceleration and in the end, there is little difference in the front position between flows with or without basal entrainment. PIV was used in the entrainment zone to measure internal velocities away from the sidewalls, and it was found that velocities were stronger when the depth of the stationary layer was increased. Differential seeding of the bed and the current allowed the identification of the flow/bed interface, which made it possible to monitor its progression.

With our physical intuition, we did not anticipate that a simple lubrication model like Huppert's would perform so well in this situation. The model showed good agreement in the following comparisons:

- The modeled surface was a good reproduction of that found in experiments.

- In both model and experiments, the presence of a stationary layer accelerated the flow front $x_{F}(t)$. 
- The progression of the flow front was in close agreement in model and experiments.

- Similar velocity distributions were found in the PIV analysis and the model results, but the relative error between theory and experiment was as high as $50 \%$.

- The model performed fairly well over longer distances, even with a lower viscosity fluid (i.e., at higher Reynolds numbers).

While the Newtonian model has sometimes been used to describe the flow behavior of natural materials such as snow and debris suspensions, ${ }^{51,52}$ the majority of existing approaches rely on more elaborate constitutive equations. ${ }^{53}$ Moreover, for natural gravity-driven flows, basal entrainment occurs mostly on steep slopes, whereas here we focus on a horizontal setup. So there is no direct application of the results presented here to real flow conditions. Yet, our study sheds light on the mechanisms involved in basal entrainment and the most convenient way to quantify these. We provide evidence that the whole layer of loose material is entrained quickly once the flow makes contact with the stationary layer: an acceleration wave propagates across the bed and sets fluid into motion. As this process occurs on very short times (typically less than $0.1 \mathrm{~s}$ in our experiments), we can consider that the whole layer underneath the incoming flow is mobilized instantaneously. The consequence is that the modeling is quite simple: the flow depth is instantaneously increased by the thickness of the stationary layer. Experiments show that resulting governing equation (12) performs well in the limit of low Reynolds numbers. This process brings to mind other instances of fast basal entrainment of loose material in avalanches ${ }^{19}$ and debris flows. ${ }^{20}$ It should also be noted that extended Huppert's equation (12) can be cast in a form reminiscent of mass balance equation (1) used within the Saint-Venant approach for modeling eroding flows by taking $\bar{u}=-\varrho g(h-B)^{2} \partial_{x} h /(3 \mu)$ and $E=0$ (consistently with our results, which show that basal entrainment occurs instantaneously and so the entrainment rate $E$ should drop to zero).

\section{ACKNOWLEDGMENTS}

The work presented here was supported by the Swiss National Science Foundation under Grant No. 200021_146271/1, a project called "Physics of Basal Entrainment." The authors are grateful to Bob de Graffenried for his technical assistance, to three anonymous reviewers for their feedback and to Anne Mangeney, François Gallaire, and Marco Ramaioli for frank and encouraging discussions. The data shown in Figs. 7, 8, and 13 (together with the MatLab script used for computing $x_{F}(t)$ ) are available from the figshare data repository: http://dx.doi.org/10.6084/m9.figshare.2057748.

\section{APPENDIX: ERROR QUANTIFICATION}

Quantification of errors in PIV is difficult, and therefore defining strict error bounds on $(u, w)$ is troublesome. The other errors originating from measurements are discussed here.

- Volume/mass of fluid. The mass was measured by weighing the container before and after the fluid had been extracted to be put in the flume reservoir. This was accurate to within $10 \mathrm{~g}$. During the flow, some fluid was lost down the sides of the inserted steps. The maximum estimate for lost fluid is $1.5 \mathrm{ml}$ based on the size of the two thin gaps either side, which is maximum $0.18 \%$ of the $800 \mathrm{ml}$ Newtonian fluid released for campaign A.

- The setup lengths were measured with a tape measure or ruler with $1 \mathrm{~mm}$ markers, and therefore are accurate to within around $1 \mathrm{~mm}$.

- Viscosity of glycerol. This was a tricky parameter to control due to the great sensitivity of $\mu$ to any change in air temperature or humidity. An Ostwald viscometer tube was used to measure viscosity for campaigns $\mathrm{A}$ and $\mathrm{C}$. From the different tests we made, we deduced that the uncertainty on $\mu$ was around $1 \%$. The PIV experiments of campaign B were performed earlier than campaigns A and C. For that campaign, the viscosity was calculated by measuring specific gravity of the glycerol concentration (using a hydrometer) and reading its viscosity from a table.

- Measurements from cameras 2 and 3. Using the calibration grids, camera 2's resolution was roughly 2 pixels/mm and camera 3's resolution was around 3 pixels $/ \mathrm{mm}$. Thus measurements 

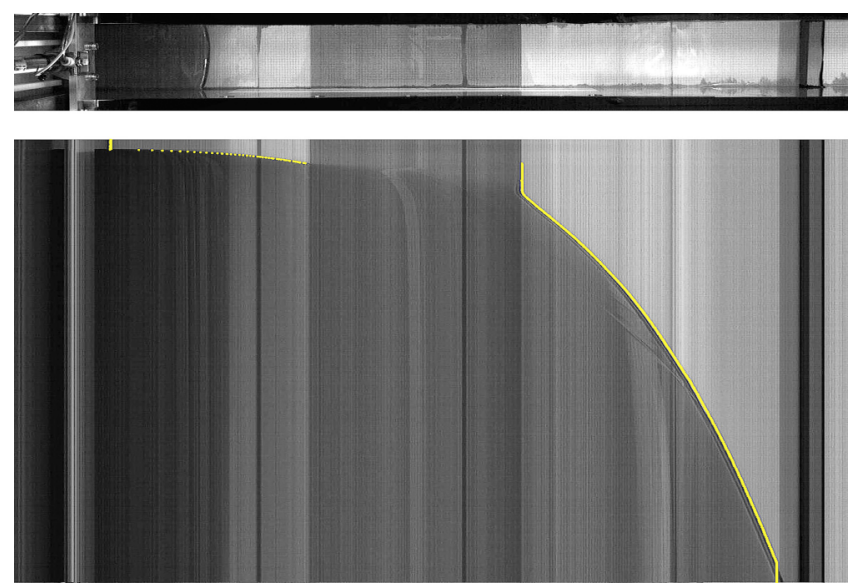

FIG. 14. Space-time plot of flow front from camera 2.

from these two cameras (flow depth and front position) can be estimated to be accurate to within $1 \mathrm{~mm}$, taking into account effects such as shadows in camera 2 and surface curvature in camera 3. In Fig. 14, a time-space plot is shown to illustrate the progression of the front. It was created by sampling a central line of pixels at each time step. This figure shows the problem of calculating the position of the front as it passed over the stationary layer. The front position was found using image processing techniques in MatLab, which identified the interface between the dark color of the flowing material and the light color of the rigid base. The flow front contains uplifted bed material, and so the stationary layer was also chosen to be dyed blue. Unfortunately, this meant that camera 2 could not provide accurate flow front measurements over the stationary layer, and measurements had to be supplemented with data from camera 3.

${ }^{1}$ P. E. Dimotakis, “Turbulent mixing,” Annu. Rev. Fluid Mech. 37, 329-356 (2005).

2 J. S. Turner, Buoyancy Effects in Fluids (Cambridge University Press, Cambridge, 1973).

3 J. E. Simpson, "Gravity currents in the laboratory, atmosphere, and ocean," Annu. Rev. Fluid Mech. 14, 213-234 (1982).

${ }^{4}$ M. Ungarisch, An Introduction to Gravity Currents and Intrusions (CRC Publishers, Boca Raton, 2009).

${ }^{5}$ S. Legg, "Overflows and convectively driven flows," in Buoyancy-Driven Flows, edited by E. Chassignet, C. Cenedese, and J. Verron (Cambridge University Press, Cambridge, 2012), pp. 203-239.

${ }^{6}$ B. Sovilla, P. Burlando, and P. Bartelt, "Field experiments and numerical modeling of mass entrainment in snow avalanches," J. Geophys. Res.: Earth Surf. 111, F03007, doi:10.1029/2005jf000391 (2006).

${ }^{7}$ O. Hungr, S. McDougall, and M. J. Bovis, "Entrainment of material by debris flows," in Debris-Flow Hazard and Related Phenomena, edited by M. Jakob and O. Hungr (Springer, Berlin, 2005), pp. 135-158.

${ }^{8}$ F. Legros, "The mobility of long-runout landslides," Eng. Geol. 63, 301-331 (2002).

${ }^{9}$ M. Farin, A. Mangeney, and O. Roche, "Fundamental changes of granular flow dynamics, deposition, and erosion processes at high slope angles: Insights from laboratory experiments," J. Geophys. Res.: Earth Surf. 119, 504-532, doi:10.1002/2013jf002750 (2014).

${ }^{10}$ G. Parker, "Conditions for the ignition of catastrophically erosive turbidity currents," Mar. Geol. 46, 307-327 (1982).

${ }^{11}$ C. Ancey, "Powder-snow avalanches: Approximation as non-Boussinesq clouds with a Richardson-number-dependent entrainment function,” J. Geophys. Res.: Earth Surf. 109, F01005, doi:10.1029/2003jf000052 (2004).

12 P. Gauer and D. Issler, "Possible erosion mechanisms in snow avalanches," Ann. Glaciol. 38, 384-392 (2003).

13 A. Dufresne, "Granular flow experiments on the interaction with stationary runout path materials and comparison to rock avalanche events," Earth Surf. Processes Landforms 37, 1527-1541 (2012).

${ }^{14}$ G. Parker, M. García, Y. Fukushima, and W. Yu, "Experiments on turbidity currents over an erodible bed," J. Hydraul. Res. 25, 123-147 (1987).

${ }^{15}$ R. M. Iverson, "Elementary theory of bed-sediment entrainment by debris flows and avalanches," J. Geophys. Res.: Earth Surf. 117, F03006, doi:10.1029/2011jf002189 (2012).

${ }^{16}$ B. Quan Luna, A. Remaître, T. W. J. van Asch, J. P. Malet, and C. J. van Westen, "Analysis of debris flow behaviour with a one dimensional run-out model incorporating entrainment," Eng. Geol. 128, 63-75 (2012).

${ }^{17}$ R. M. Iverson and D. L. George, "A depth-averaged debris-flow model that includes the effects of evolving dilatancy. I. Physical basis," Proc. R. Soc. London, Ser. A 470, 20130819 (2014).

${ }^{18}$ M. Y. Louge, C. S. Carroll, and B. Turnbull, "Role of pore pressure gradients in sustaining frontal particle entrainment in eruption currents: The case of powder snow avalanches," J. Geophys. Res. 116, F04030, doi:10.1029/2011jf002065 (2011).

${ }^{19}$ C. Ancey, "Modélisation des avalanches denses, approches théorique et numérique," La Houille Blanche 5-6, 25-39 (1994). 
${ }^{20}$ C. Berger, B. W. McArdell, and F. Schlunegger, "Direct measurement of channel erosion by debris flows, Illgraben, Switzerland,” J. Geophys. Res.: Earth Surf. 116, F01002, doi:10.1029/2010jf001722 (2011).

${ }^{21}$ S. W. McCoy, J. W. Kean, J. A. Coe, D. M. Staley, T. A. Wasklewicz, and G. E. Tucker, "Evolution of a natural debris flow: In situ measurements of flow dynamics video imagery, and terrestrial laser scanning," Geology 38, 735-738 (2010).

${ }^{22}$ F. Herman, O. Beyssac, M. Brughelli, S. N. Lane, S. Leprince, T. Adatte, J. Y. Y. Lin, J.-P. Avouac, and S. C. Cox, "Erosion by an Alpine glacier," Science 350, 193-195 (2015).

${ }^{23}$ D. Issler, "Experimental information on the dynamics of dry-snow avalanches," in Dynamic Response of Granular and Porous Materials under Large and Catastrophic Deformation, edited by K. Hutter and N. Kirchner (Springer, Berlin, 2003), pp. 109-160.

${ }^{24}$ B. Sovilla, J. McElwaine, and M. Y. Louge, "The structure of powder snow avalanches," C. R. Phys. 16, 97-104 (2015).

${ }^{25}$ R. M. Iverson and C. Ouyang, "Entrainment of bed material by Earth-surface mass flows: Review and reformulation of depth-integrated theory,” Rev. Geophys. 53, 27-58, doi:10.1002/2013RG000447 (2015).

${ }^{26}$ Y. C. Tai and C. Y. Kuo, "A new model of granular flows over general topography with erosion and deposition," Acta Mech. 199, 71-96 (2008).

${ }^{27}$ L. Lê and E. B. Pitman, "A model for granular flows over an erodible surface,” SIAM J. Appl. Math. 70, 1407-1427 (2009).

${ }^{28}$ J. M. N. T. Gray, "Granular flow in partially filled slowly rotating drums," J. Fluid Mech. 441, 1-29 (2001).

${ }^{29}$ H. Capart, C. Y. Hung, and C. P. Stark, "Depth-integrated equations for entraining granular flows in narrow channels," J. Fluid Mech. 765, R4 (2015).

${ }^{30}$ P. Chadwick, Continuum Mechanics: Precise Theory and Problems (Dover, Mineola, 1999).

${ }^{31}$ A. Armanini, H. Capart, L. Fraccarollo, and M. Larcher, "Rheological stratification in experimental free-surface flows of granular-liquid mixtures," J. Fluid Mech. 532, 269-319 (2005).

32 C. C. Mei, "Nonlinear gravity waves in a thin sheet of viscous fluid," J. Math. Phys. 45, 266-288 (1966).

${ }^{33}$ C. Nakaya, "Spread of fluid drops along a horizontal plane," J. Phys. Soc. Jpn. 37, 539-543 (1974).

${ }^{34} \mathrm{H}$. E. Huppert, "The propagation of two-dimensional and axisymmetric viscous gravity currents over a rigid horizontal surface," J. Fluid Mech. 121, 43-58 (1982).

${ }^{35}$ R. E. Grundy and R. McLaughlin, "Large-time solution of a nonlinear diffusion equation," Proc. R. Soc. London, Ser. A 381, 395-406 (1982).

${ }^{36}$ N. Didden and T. Maxworthy, "The viscous spreading of plane and axisymmetric gravity currents," J. Fluid Mech. 121, 27-42 (1982).

${ }^{37}$ J. Gratton and F. Minotti, "Self-similar viscous gravity currents: Phase-plane formalism," J. Fluid Mech. 210, 155-182 (1990).

${ }^{38}$ C. Ancey, S. Cochard, and N. Andreini, “The dam-break problem for viscous fluids in the high-capillary-number limit," J. Fluid Mech. 624, 1-22 (2009).

${ }^{39}$ R. V. Craster and O. K. Matar, "Dynamics and stability of thin liquid films," Rev. Mod. Phys. 81, 1131-1198 (2009).

${ }^{40}$ Y. Hallez and J. Magnaudet, "A numerical investigation of horizontal viscous gravity currents," J. Fluid Mech. 630, 71-91 (2009).

${ }^{41}$ E. J. Watson, "Boundary-layer growth,” Proc. R. Soc. A 231, 104-116 (1955).

${ }^{42}$ R. D. Skeel and M. Berzins, "A method for the spatial discretization of parabolic equations in one space variable," SIAM J. Sci. Stat. Comput. 11, 1-32 (1990).

${ }^{43}$ A. A. Lacey, J. R. Ockendon, and A. B. Tayler, "Waiting-time solutions of a nonlinear diffusion equation," SIAM J. Appl. Math. 42, 1252-1264 (1982).

${ }^{44}$ L. P. Thomas, B. M. Marino, and R. Gratton, "Waiting-time behavior for large angle wedges of viscous liquids," Phys. Rev. Lett. 78, 654 (1997).

45 J. F. Blowey, J. R. King, and S. Langdon, "Small- and waiting-time behavior of the thin-film equation," SIAM J. Appl. Math. 67, 1776-1807 (2007).

${ }^{46}$ M. Raffel, C. E. Willert, S. T. Wereley, and J. Kompenhans, Particle Image Velocimetry (Springer, Berlin, 2007).

${ }^{47}$ J. K. Sveen, "An introduction to MatPIV," Technical Report e-print Series No. 2, Mechanics and Applied Mathematics, Department of Mathematics, University of Oslo, 2004, http://folk.uio.no/jks/matpiv/.

${ }^{48}$ B. M. Wilson and B. L. Smith, "Uncertainty on PIV mean and fluctuating velocity due to bias and random errors," Meas. Sci. Technol. 24, 035302 (2013)

${ }^{49}$ B. M. Bates, C. Ancey, and J. Busson, "Visualization of the internal flow properties and the material exchange interface in an entraining viscous Newtonian gravity current," Environ. Fluid Mech. 14, 501-518 (2014).

${ }^{50}$ N. Andreini, G. Epely-Chauvin, and C. Ancey, "Internal dynamics of Newtonian and viscoplastic fluid avalanches down a sloping bed," Phys. Fluids 24, 053101 (2012).

${ }^{51}$ B. Hunt, "Newtonian fluid mechanics treatment of debris flows and avalanches," J. Hydraul. Eng. 120, 1350-1363 (1994).

52 J. D. Dent and T. E. Lang, "A biviscous modified Bingham model of snow avalanche motion," Ann. Glaciol. 4, 42-46 (1983).

${ }^{53}$ C. Ancey, "Gravity flow on steep slope," in Buoyancy Driven Flows, edited by E. Chassignet, C. Cenedese, and J. Verron (Cambridge University Press, New York, 2012), pp. 372-432. 